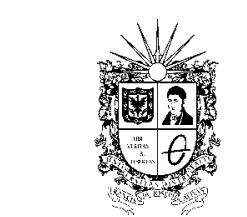

UNIVERSIDAD DISTRITAL FRANCISCO JOSE DE CALDAS

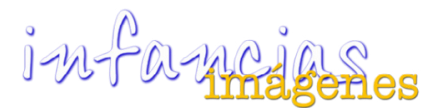

http://revistas.udistrital.edu.co/ojs/index.php/infancias

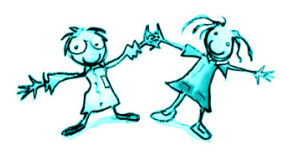

SEPARATA ESPECIAL

\title{
Libro álbum: un camino de creación literaria y trabajo colaborativo con niños y niñas
}

\author{
Johanna Paola Lozano Luisa Fernanda Moreno ${ }^{2}$ Nazly Giselle Vargas ${ }^{3}$
}

\section{Resumen}

Este artículo describe una propuesta metodológica y un camino de descubrimientos en el proceso de investigación/creación, que comienza con la realización del libro álbum La coleccionista de abuelas y continúa con una apuesta por el trabajo en colaboración con niños como coautores, escritores e ilustradores de un libro álbum para público infantil.

Palabras clave: libro ilustrado, literatura infantil, experiencia creativa, escritura, ilustración, trabajo colaborativo.

\section{Abstract}

This article describes a methodological proposal and a path of discoveries in the research / creation process, which begins with making of illustrated album La COleccionista de abuelas (The Collector of Grandmothers) and continues with a bet to collaborative work with children as coauthors, writers and illustrators of a book album for children.

Keywords: picture book, children's literature, creative experience, writing, illustration, collaborative work.

\section{Introducción}

La investigación de la que se pretende dar cuenta en el presente artículo inicia con una búsqueda personal de expresión y acercamiento a la infancia, una indagación por la producción de literatura infantil en Colombia y los temas que se abordan en ella, personajes e imágenes a los que los primeros lectores tienen acceso, de allí nace el proceso de creación del libro álbum La coleccionista de abuelas, un objeto artístico y literario que pretende acercar a los niños y las niñas a contenidos relacionados con la diversidad cultural de Colombia, aportando a la construcción de las narrativas infantiles y al desarrollo de la identidad cultural desde la experiencia literaria.

Este proceso de creación rescata la figura de la abuela como un personaje representativo de las tradiciones, una posibilidad de encuentro con el territorio colombiano y sus particularidades culturales, a través de Ana, una niña de 6 años, amante de las colecciones. Por otro lado, marca un camino de aprendizaje de lo que significa escribir para niños, que desde la concepción de esta investigación surge como el deseo de crear una posibilidad abierta a su imaginación, sentimientos y pensamientos, con la clara premisa de que todos los niños y niñas tienen derecho a acceder a contenidos de alta calidad que les permitan explorar, aprender y divertirse; que les abran las puertas a la cultura y diversidad de nuestro país. La narradora y poetisa Vian afirma: "Escribir para niños significa una gran responsabilidad, porque uno sabe que tiene la posibilidad de sembrar ideas, sueños y determinada sensibilidad en sus lectores" (1995, p. 10).

Es nuestro propósito compartir el proceso de creación del libro álbum La coleccionista de

\footnotetext{
Licenciada en Educación Básica con énfasis en Educación Artística.

2 Profesional en Medios Audiovisuales, con énfasis en Dirección y Producción de Cine.

3 Licenciada en Educación Básica con énfasis en Educación Artística.
} 
abuelas, así como dar a conocer un camino hacia la co-creación, un término que, desde la producción de contenidos para la infancia, definimos como el trabajo conjunto entre el autor y su público objetivo para la creación colectiva de un producto que le dé la posibilidad de participación activa a los niños y niñas, y de esta manera construir un lenguaje visual y narrativo idóneo para el público infantil.

Soriano afirma: "La madurez y el nivel de desarrollo que adquiera un niño van a depender de la cantidad y calidad de sus experiencias: la experiencia literaria es rica en valores por ser una experiencia real, estética y social" (1995, p. 168), pero si además de ser un lector en la experiencia literaria, existiesen escenarios donde el niño fuese autor, se potenciaría mucho más esta experiencia, no solo para quien produce sino para quien lee, pues de esta manera el público infantil tendría la oportunidad de encontrarse con un relato más cercano a sus imaginarios del mundo.

Además, resaltamos la importancia de que existan especialistas en infancia dedicados a procesos de creación, que cuenten con la motivación, los conocimientos y las habilidades para construir objetos literarios, con contenidos acordes a los intereses y necesidades del público infantil. Por supuesto partiendo de la premisa de que "en un libro álbum confluyen distintos lenguajes. Por lo tanto, son necesarios distintos talentos" (Ministerio de Educación República de Chile, 2009, p. 80).

\section{El libro állbum}

El libro álbum se destaca en la literatura infantil como una obra representativa, un género único con una característica particular, la conexión de dos lenguajes, el visual y el textual, en el que la imagen y las palabras se conectan para dar vida a una historia. Fanuél Díaz, crítico e investigador literario expone:

En los libros álbumes no basta con que exista esta interconexión de códigos, debe prevalecer tal dependencia que los textos no puedan ser entendidos sin las imágenes y viceversa [...]. Incluso en algunos casos el lector se encarga de llenar esos intervalos de sentido que se obtiene por el tejido que ambos códigos construyen $(2007$, p. 8).
En esta investigación se abordó el libro álbum como una posibilidad de creación, donde los valores estéticos y literarios se complementan para despertar los sentidos y las emociones del lector. Se trata de un formato que permite la interacción perfecta entre el texto y la imagen, una característica de gran significado para los primeros lectores, que poseen un auténtico interés y capacidad para la lectura de imágenes.

El libro álbum es un género reciente y en crecimiento, que actualmente cuenta con producciones a nivel mundial, pero, ¿qué libros álbumes se encuentran en las librerías y bibliotecas del país y cuáles son catalogados como literatura infantil? En la búsqueda de una respuesta se desarrolló una indagación por diferentes bibliotecas y librerías de Bogotá, algunas de ellas especializadas en contenidos para infancia y otras que cuentan con salas pensadas para el público infantil.

Para organizar la información obtenida en esta etapa de la investigación se construyó una matriz ${ }^{4}$ en la que se definieron 20 categorías, que se agruparon en tres secciones: la primera, Ubicación bibliográfica, describe la localización del libro en las diferentes bibliotecas y librerías visitadas; la segunda, Información de los creadores, expone una corta reseña de cada autor e ilustrador, y la tercera, Descripción del libro álbum, describe el contenido del libro y las características de este en términos de forma y diseño.

A continuación se exponen tres conclusiones del análisis de la matriz descrita, la cual se completó con 41 publicaciones, siendo esta el primer acercamiento de nuestra investigación en la producción de libro álbum del país y la oferta en la ciudad de Bogotá:

1. Las producciones de autores o ilustradores colombianos no superan una cuarta parte de los libros álbumes expuestos en las secciones de literatura infantil, además, exceptuando el Centro de Cultura Económica Gabriel García Márquez y la Librería Babel, no existe una clasificación física o en catálogo que le permita a niños o

\footnotetext{
4 Anexo 1. Trabajo de investigación "Creación: libro álbum La coleccionista de abuelas". http://repository.udistrital.edu.co/handle/11349/2533.
} 
adultos buscar libros de autores o ilustradores colombianos de una manera sencilla y eficaz.

2. Desde hace aproximadamente tres décadas hay un interés importante en la producción de libros infantiles en Colombia, por esto aparecen nuevas editoriales como Babel y GatoMalo, interesadas en este género y también otras con más trayectoria como Alfaguara y Tragaluz, que se interesan por abrir un espacio para estas producciones; así se destaca el compromiso por publicar contenidos de calidad, narrativos y estéticos, para otorgar un lugar muy especial al libro álbum como objeto artístico.

3. La oferta de libros álbumes dirigidos a público infantil con una mirada o un reconocimiento hacia el territorio colombiano es escasa, aunque encontramos autores, ilustradores y editoriales nacionales interesados en plasmar las problemáticas contemporáneas de nuestro país y rescatar la producción de libros de alta calidad para público infantil, evidenciamos pocas producciones literarias de autoría colombiana, que les muestren a los niños características y particularidades de nuestro territorio.

\section{Ruta del proceso creativo}

De acuerdo con los objetivos trazados al iniciar el proyecto se planteó un diseño metodológico desde la investigación/creación, como una propuesta de investigación propia del campo de las artes, que se concibe como una forma de crear y conceptualizar una práctica artística y creativa. Investigadores como Daza respaldan esta apuesta:

Desde las disciplinas del arte y del diseño se puede hacer investigación, si se consideran los diversos métodos utilizados por estas disciplinas como posibles métodos investigativos, pero es imprescindible comprender que el solo hecho de hacer una obra de arte no puede ser considerada investigación, esto estaría inmerso en el proceso investigativo, ya que este debe ofrecer unos resultados, un método y unas conclusiones que puedan ser reutilizadas por otros investigadores (2009, p. 92).

Por esta razón, en la implementación metodológica de este proyecto surgieron inquietudes frente a una ruta que permitiera sistematizar la experiencia creativa, y así evidenciar su naturaleza y la complejidad que conlleva visibilizar todas las acciones desarrolladas por los artistas para llegar al objeto final. Estas particularidades no se encontraron estipuladas dentro de los enfoques cualitativo y cuantitativo, por lo que fue necesario indagar por los procesos creativos que implementan escritores e ilustradores de libros para público infantil en Colombia, como una forma de iniciar, mediante la observación de la experiencia del otro como punto de partida válido.

A partir de esto se hicieron dos entrevistas que permitieron un acercamiento al trabajo realizado en el campo de la literatura infantil, inicialmente a Paula Bossio diseñadora gráfica, autora de El lápiz, Los diferentes y Había una vez tal vez; y posteriormente a Dipacho, diseñador gráfico, autor e ilustrador de los libros Jacinto y María José, Viernes verdes, El animal más feroz, entre otros, dos referentes de suma importancia en la creación contemporánea de contenidos literarios. En esta indagación fue posible conocer acerca de su inmersión en el mundo de la escritura, su relación con la infancia y sus procesos de creación de libros álbumes.

A continuación se presentan algunos apartados de las entrevistas que permiten identificar las particularidades de los procesos creativos de los autores:

Bossio revela que el punto de partida de sus obras son sus propias experiencias, vivencias y cuestionamientos personales.

Normalmente siempre lo que yo hago, o lo que me cautiva, o de lo que puedo hablar realmente es de mis experiencias y como las traduzco. Me gusta mucho el tema de hacer metáforas, no decirlo explícitamente [...]. Mis inquietudes más profundas son con respecto a la existencia del ser humano, a lo que nos hace diferentes, a lo que nos liga [...]. No me preocupo tanto por el niño, porque si uno se preocupa tanto en su grupo objetivo se descuida lo que se quiere decir desde uno, pero yo pienso que es decirlo desde una manera

\footnotetext{
3 Huitoto: refiere a una etnia o comunidad indígena de la Amazonía colombiana y peruana, cuyo territorio originario se encontraba en la parte media del río Caquetá y sus afluentes, y la zona selvática que va hasta el río Putumayo en Colombia.
} 
muy sencilla, que te entiendan. Todos somos seres humanos y a todos nos acogen las mismas preocupaciones. A un adulto lo acoge la soledad, a mí me acoge la soledad, a un niño lo acoge la soledad [...]. Entonces, para mí, es empezar a coger todas esas situaciones de la vida que nos hacen tan humanos y volverlas historias, eso es como lo que yo pienso y desde el punto del que yo parto. Con un lenguaje sencillo y mucho más gráfico [...]. Por ejemplo, El lápiz es un libro que habla de los encuentros maravillosos, cómo una línea te lleva a este personaje y no a ese otro (Comunicación personal, 11 de abril de 2015).

En relación al proceso de creación de Dipacho de forma general cuenta los momentos más relevantes en la construcción de sus libros álbumes:

Pues el proceso empieza por las libretas, las libretas es donde estoy anotando todo lo que se me viene a la cabeza, todo lo que estoy viviendo, escuchando, todo lo que me interesa, después de eso pues habrá personajes, o habrá ideas, o habrá anotaciones, o alguna cosa que me llame la atención, que de pronto me haga pensar en una historia y cuando ya está esa historia en mi mente, pues empiezo a pensar en un proceso un poco más cercano a la elaboración de un libro, en ese proceso de creación del libro empezaría de pronto como con una escaleta que es como el resumen de cada página [...] luego un storyboard que es donde de pronto ya en cuadros pequeños voy dibujando en escala lo que va pasar más adelante, luego muchas bocetos mucha exploración con los personajes, exploración técnica también [...], viendo como qué técnica le conviene más al libro que estoy haciendo, [...] y después ya viene como un proceso de maqueta del libro para ver cómo puede ir [...] y por último, la parte ya más como de digitalizar y de montar en los programas de diseño (Comunicación personal, 12 de mayo de 2015).

Tales aproximaciones permitieron no solo conocer de cerca experiencias en el mundo de la creación de contenidos para público infantil, sino también los procesos de investigación que cada uno de estos escritores e ilustradores lleva a cabo en el camino de materializar una obra.

Todo escritor de literatura infantil debe tener una postura en la que reconozca a los niños como sujetos de derechos, sin subestimar sus capacidades críticas y lectoras, evitando mimetizar o limitar las acciones y el lenguaje en los relatos que escribe para ellos, pero a la vez siendo considerado con su lugar en el mundo. Como concluye Chericián: "Con los niños — en la vida y en la literatura — hay que establecer una comunicación natural, sin afectaciones de ningún tipo. [...] los niños son capaces de entender muchas más cosas de las que nosotros podemos suponer" (1995, p. 11).

Frente a lo anterior, se concluye que no existe una ruta establecida para un proceso creativo, estas experiencias varían y se transforman de manera constante, tanto como el autor lo propicie. Por otro lado, aunque se evidencian unas etapas para el desarrollo de la obra, se percibe que no hay una estructura definida para su proceso de creación, todo lo contrario, como artistas, permiten que cada historia fluya y emerja a su ritmo. Ruy Vidal afirma:

No existe el arte para niños. Existe el Arte. No existen las ilustraciones para niños, existen las ilustraciones. No existe la literatura para niños, existe la Literatura. [...] Partiendo de esos cuatro principios, podemos decir que un libro para niños es un buen libro, cuando es buen libro para todos (1976).

Sin embargo, no se puede desconocer que los niños atraviesan por diferentes etapas del desarrollo y cada una de estas requiere de unas consideraciones particulares por parte de quien emprende la labor de producir contenidos dirigidos al público infantil, en términos de lenguaje, estructuras narrativas, tiempos verbales, diseño, ilustración, entre otros.

\section{Primer cuadro: 'La coleccionista de} abuelas ${ }^{5}$

Para el libro álbum La coleccionista de abuelas, se trazó una ruta de acciones con un enfoque plástico y literario que se materializó a través de unos Laboratorios Creativos, entendidos estos como los espacios de experimentación y conceptualización alrededor

\footnotetext{
5 Este momento corresponde a la realización de la investigación y trabajo de grado para obtener el título de Especialistas en Infancia, Cultura y Desarrollo de la Universidad Distrital Francisco José de Caldas.
} 
de una obra. Cada laboratorio fue concebido como un lugar de encuentro, de intercambio de saberes y conocimiento, que apoyados en la indagación previa, permitieron esbozar un camino propicio para la creación del libro álbum La coleccionista de abuelas. Aunque se desarrollaron en numerosas sesiones, a continuación se compartirán los momentos y resultados más significativos de los laboratorios.

\section{Laboratorios de creación}

Se desarrollaron alrededor de: escritura, ilustración, técnicas, materiales y estética. A continuación se presentan algunas generalidades sobre cada uno de ellos.

\section{Laboratorios de escritura \\ A. Exploración y crecimiento de ideas}

Los primeros laboratorios se orientaron a partir de las propuestas de los libros La cocina de la escritura, de Daniel Cassany (1996); El regalo de la escriXIV tura, de Clemencia Cuervo y Rita Flórez (2015), y Escribir para niños, de Silvia Kohan, los cuales plantean un cuestionamiento sobre qué se quería contar y cómo contárselo a los niños; además brindaron una orientaron frente a la definición del problema retórico de nuestro libro álbum, el accionar de las siguientes ideas principales y cómo desarrollarlas:

- Particularidades del territorio colombiano.

- Saberes de las abuelas.

- Tradiciones culturales.

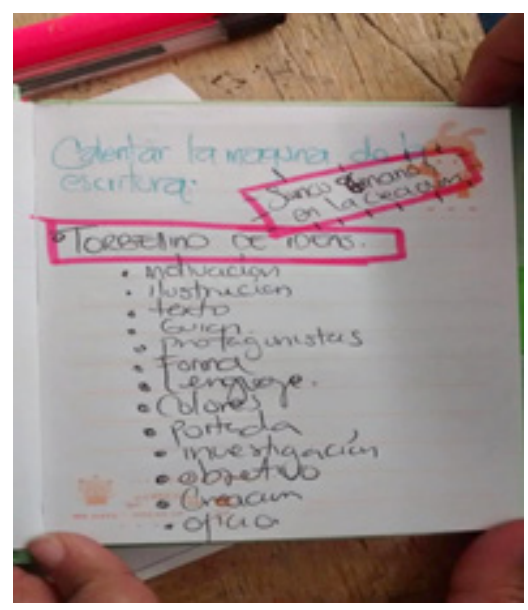

Figura 1. Torbellino de ideas. Fuente: elaboración propia.

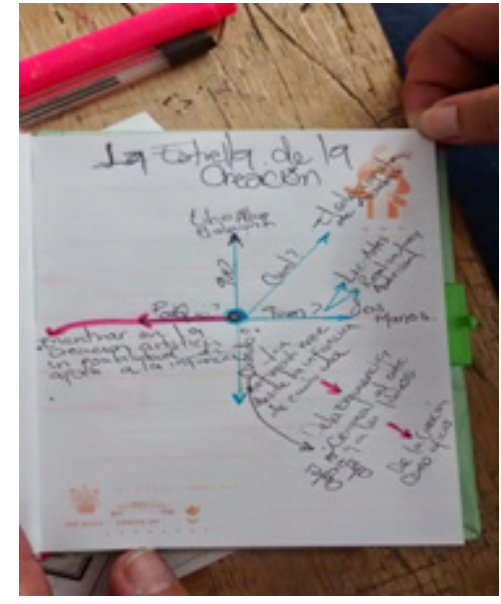

Figura 2. La estrella de la creación. Fuente: elaboración propia.

\section{B. Desarrollo de la historia}

Este proceso a tres voces requirió tiempo, amor, paciencia y rigurosidad para encontrar una voz narrativa. Resultó una labor ardua y, a la vez gratificante, que se tornó en una oportunidad de aprendizajes y encuentros de la imaginación y de la palabra, que incluso nos trasladó hasta los mundos literarios de nuestra propia infancia. Es importante mencionar que este laboratorio se desarrolló de manera transversal a todo el proceso de creación e implicó constantes modificaciones y revisiones con el fin de encontrar los elementos claves de la historia.

\section{Guion - Escaleta}

Este laboratorio se desarrolló de forma transversal; los guiones se elaboraron a la par con las historias, ya que se consideró importante visualizar de manera concreta cómo iba a ser narrada La coleccionista de abuelas.

Así mismo el guion permitió pensar y definir una voz narrativa acorde al público infantil, con la cual se precisaron parámetros textuales y visuales, dados desde la correlación de estos dos medios y desde la capacidad de abstracción de los posibles lectores.

Este espacio fue una herramienta clarificadora de ideas, pues permitió transformar la historia en texto e imágenes, dando los primeros pasos a una estética visual surrealista que mezcla la fantasía y la realidad.

\section{Laboratorios de ilustración \\ A. Construcción de personajes}

En el proceso de creación literaria los personajes fueron emergiendo a medida que la historia tomaba 
fuerza, poco a poco algunas de las características principales de cada uno de los protagonistas de $\mathrm{La}$ coleccionista de abuelas se hicieron evidentes.

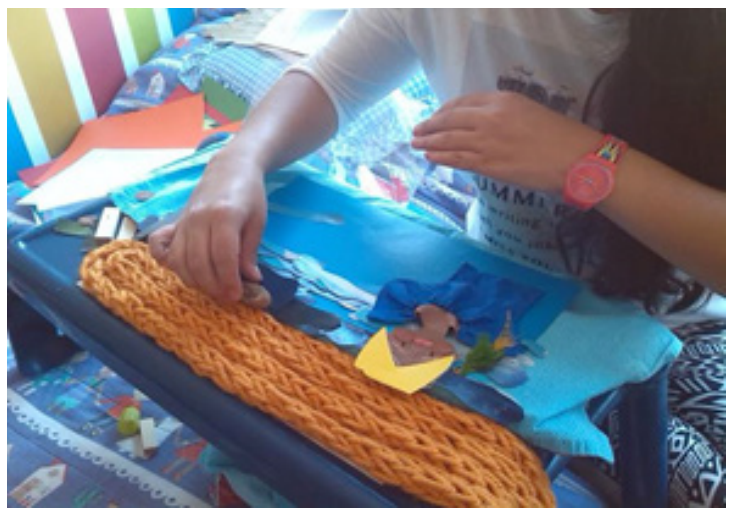

Figura 3. Prueba abuela Chocó.

Fuente: elaboración propia.

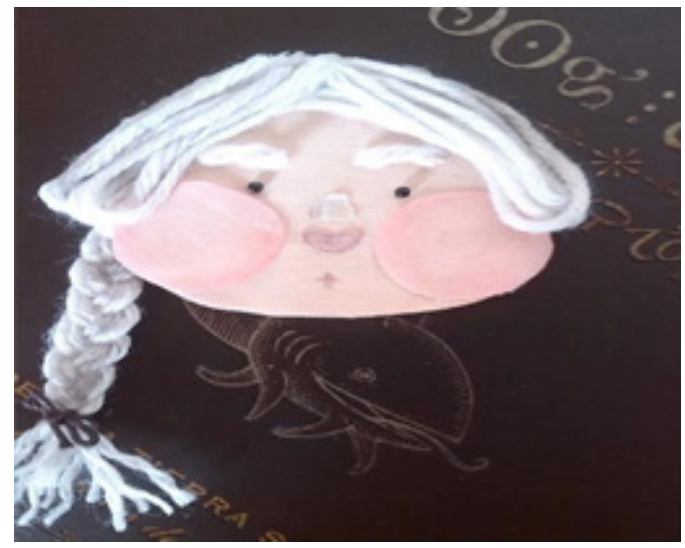

Figura 4. Prueba abuela Boyacá.

Fuente: elaboración propia.

\section{B. Storyboard}

Resaltando nuestra obra como un objeto artístico y literario fue necesario incluir en el proceso creativo una serie de bocetos que sirvieran como medio para precisar su concepto visual y narrativo.

Así, a través del storyboard, en viñetas a pequeña y mediana escala se fue definiendo la composición visual de cada página, donde se resaltó el poder narrativo de los elementos que intervienen en el libro álbum, en especial la cohesión entre el texto y la imagen; además se tuvieron en cuenta características como: tamaño de los elementos, planos, tipografía, disposición en el espacio, movimiento, superposición, vacíos e, incluso, unos primeros pasos hacia la paleta de color y los materiales como elementos de la narración.

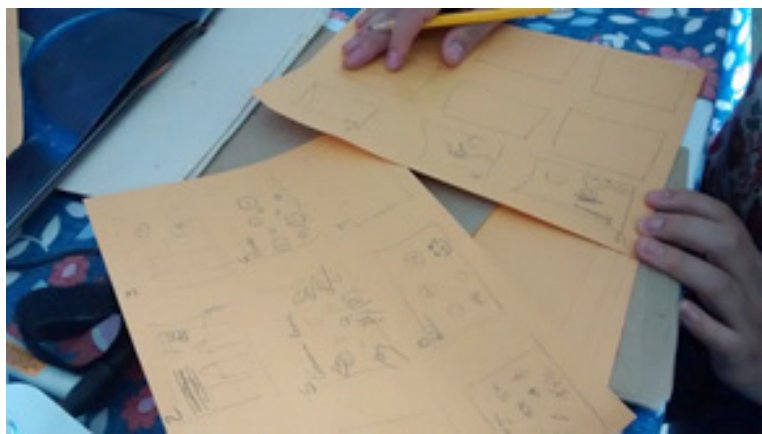

Figura 5. Bocetos del storyboard.

Fuente: elaboración propia.

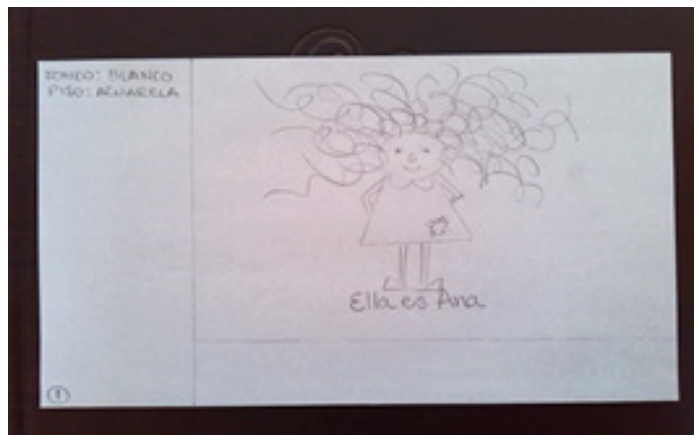

Figura 6. Página storyboard.

Fuente: elaboración propia.

3. Laboratorio de experimentación de técnicas, materiales y estética del libro álbum

Este laboratorio se basó en la experimentación de diversos elementos y materiales que dieron forma al libro álbum La coleccionista de abuelas. Muchos aspectos sobresalieron en esta etapa del proceso, cada uno de ellos fue parte esencial en el momento de concebir un producto final, que además de ser un objeto de alto contenido estético, se complementó con una manufactura acorde a las expectativas de cada una de las creadoras de este proyecto. En este punto se llevó a cabo un encuentro de imaginarios acerca de la apariencia que podría tener el libro, lo cual permitió enriquecer el proceso de creación, teniendo en cuenta que en él confluyeron aportes desde tres perspectivas diferentes.

\section{Laboratorio de digitalización}

Una vez realizadas todas las pruebas y teniendo el montaje final de cada página se dispuso el tiempo y los equipos para la digitalización de las imágenes a través de fotografías, las cuales se editaron para dar 
paso a la diagramación, en la cual se agregaron los textos para finalizar con la impresión y digitalización del libro álbum.

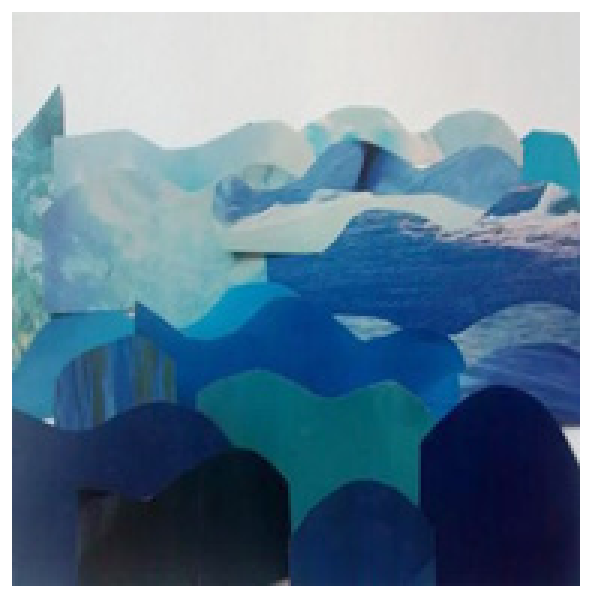

Figura 7. Prueba fondo mar.

Fuente: elaboración propia.

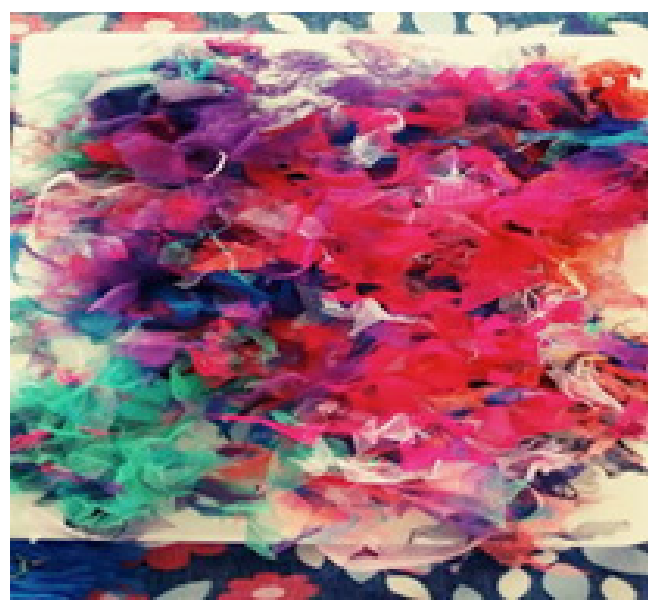

Figura 8. Prueba fondo.

Fuente: elaboración propia.

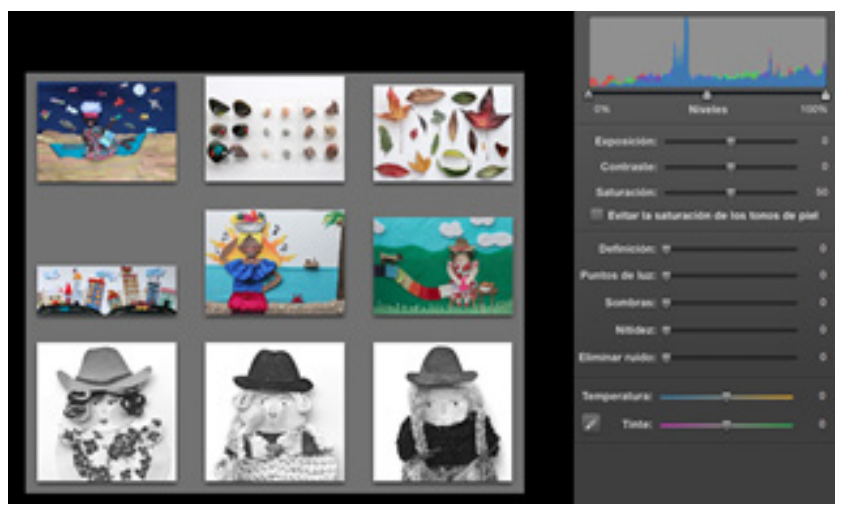

Figura 9. Edición de imagen.

Fuente: elaboración propia.

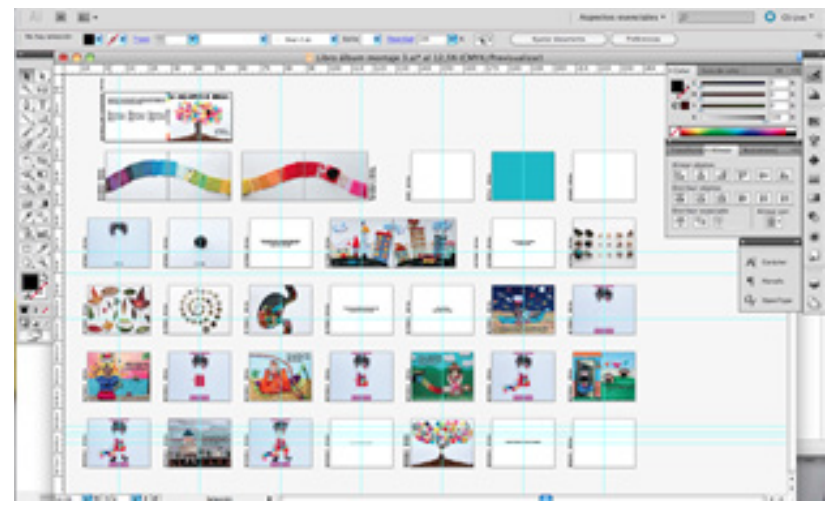

Figura 10. Diseño y diagramación digital.

Fuente: elaboración propia.

Los laboratorios descritos anteriormente fueron el eje de nuestra ruta metodológica en el proceso de investigación/creación, a través de estos descubrimos nuestra voz y la de nuestra obra; así, se creó una narración literaria y visual que concluyó con el libro álbum La coleccionista de abuelas.

\section{Segundo cuadro: creación en colabora- ción con niños ${ }^{6}$}

Recorrer un camino de creación de un libro álbum pensado para público infantil propicia la aparición de cuestionamientos sobre los intereses de los niños, sus formas de ver y pensar el mundo, al igual que las maneras de leer. El proceso de investigación/creación aquí expuesto, pese a estar contemplado desde un respeto profundo por la infancia y con la intención de producir un contenido de calidad que enriquezca el mundo infantil, suscitó una preocupación sobre la gran brecha que por años ha existido en los procesos de creación para este público. Como afirma el escritor e ilustrador Lizardo Carvajal: "La literatura infantil se ha construido desde la visión de infancia que tiene el adulto, el reto ahora es hacerlo desde la visión de los niños" (comunicación virtual, 15 de octubre de 2016).

$\mathrm{Al}$ igual que este equipo de creativas, muchos autores han pretendido representar a los niños y contemplar sus intereses, sus capacidades, sus lenguajes, sus inquietudes y puntos de vista; pero ¿qué

\footnotetext{
5 Este momento corresponde a la investigación y trabajo de grado para optar el título de Maestría en Infancia y Cultura de la Universidad Distrital Francisco José de Caldas. Trabajo dirigido por la profesora Karina Claudia Bothert.
} 
pasaría si no tuviéramos que pretender?, ¿qué tal si niños y niñas pudieran resolver estas encrucijadas de la producción de contenidos infantiles? Es así como la segunda etapa de esta investigación buscó responder estas preguntas, a partir del reconocimiento del niño como agente creador, como sujeto de lenguaje, con capacidad para narrar y expresarse desde sus relatos.

En esta segunda etapa se fusionó la investigación/creación con un enfoque etnográfico, basado en metodologías colaborativas como las desarrolladas en Diana Milstein et al., que plantea:

hacer etnografía es básicamente intentar producir, representar y re-presentar el conocimiento de otro(s) que son nuestros interlocutores. [...]. El fundamento empírico de la investigación etnográfica se basa en la clase de interacción en la que I@s etnógraf@s reconocen a sus participantes como co-productores. (2011, pp. 15-16).

Para este proyecto los niños son co-productores, ilustradores y escritores.

Al iniciar este camino se precisó ahondar en conceptos previos alrededor del fenómeno de la co-creación y la investigación en colaboración con niños, pero además desencadenó una construcción propia de las metodologías que permiten trabajar de la mano con los niños en un proceso de creación de un libro álbum para público infantil. La vOZ de los niños es la clave para seguir transitando por el camino de la creación, le apostamos a un objeto artístico y literario construido de la mano con ellos, escuchando y plasmando lo que tienen que decir al respecto.

Por esta razón, la investigación destaca las particularidades que un trabajo colaborativo requiere en cuanto al acompañamiento de un adulto consciente del papel de mediador, que potencie las acciones del niño y además propicie una relación respetuosa frente a la autonomía creadora en este proceso, una postura que se ha abordado desde ámbitos como la pedagogía, en la que exponentes como Malaguzzi afirman: "Es necesario que los adultos se sientan co-aprendices, co-descubridores, dispuestos a prestar a los niños toda la atención necesaria, ofreciéndoles los elementos para descubrir, investigar y completar o modificar ese conocimiento intuitivo expandiéndolo ilimitadamente, como son sus capacidades, ilimitadas" (citado por Correa, 2011, p. 43).

Concebimos la investigación/creación con niños como un trabajo colaborativo en el que nos disponemos junto con ellos, como pares, a descubrir con curiosidad las múltiples posibilidades de los relatos y otras narrativas, fragmentos de realidad e imaginación que constituirán la esencia del proyecto.

Para nosotros es pertinente que este ejercicio de co-creación del libro álbum parta de escuchar la voz de los niños, para darle rumbo a la producción de un objeto que permitirá trabajar una construcción de sentido de manera colectiva, materializándose no solo como un objeto literario para público infantil, sino también como un contenido que dialoga con las experiencias de vida de los niños y adultos que lo lean.

Proponemos una experiencia que sea una oportunidad de contar, crear y representar para otros; sea una posibilidad de ser escuchados, como sujetos de lenguaje, de experiencias y saberes, creadores de imágenes e historias, construidas desde sus vivencias y mezcladas con su imaginación, y sea un lugar de expresión y construcción de pensamiento tan válido como el del investigador o creador adulto.

\section{Escribir e ilustrar con niños}

Para dar inicio al proceso de creación con niños, primero se realizó una revisión alrededor de la ruta metodológica trabajada en La coleccionista de abuelas, siendo este el punto de partida para identificar aquellas herramientas claves para culminar esta obra, y que podrían ser de utilidad en esta nueva etapa de co-creación.

Conservando un enfoque plástico y literario, se realizó la búsqueda de una estrategia metodología que permitiera llevar a cabo acciones de creación con niños y niñas, encontrando en la modalidad de taller, un medio que se ajustaba a los intereses a desarrollar.

Al respecto, Borghi Quinto refiere:

Los talleres entendidos como espacios de crecimiento garantizan a las niñas y los niños la 
posibilidad de hacer cosas y, al mismo tiempo, incitan a la reflexión sobre qué están haciendo. El taller es un lugar especializado y en él se desarroIlan actividades meditadas. En el taller es posible curiosear, probar y volver a probar, concentrarse, explorar, buscar soluciones, actuar con calma, sin la obsesión de obtener un resultado a toda costa. Puede ser también una diversión y un juego. Es hacer por el placer de hacer. El taller ayuda a los niños a crecer dejándoles tiempo para crecer (2005, p. 17).

En este sentido, entendemos que a partir del taller se puede propiciar un espacio que transforme la experiencia del encuentro con el adulto, donde la autonomía, la confianza y la libertad de pensar, sentir y hacer, sean las premisas de este diálogo.

Los talleres diseñados para escribir e ilustrar con niños se dividieron en cuatro momentos de creación: Iluvia de ideas, investigación, escritura e ilus-

XVIII tración. Un orden que no significó rigidez en su desarrollo, ya que la primera experiencia de creación, dejó claro que aunque exista una línea o una ruta planificada, en el camino de la creación suelen darse momentos de giro que hacen necesario tomar decisiones para encauzar el recorrido. Todo esto con el juego como eje transversal del quehacer creador.

Para este proyecto de co-creación, cuatro niñas entre 7 y 9 años fueron invitadas a ser co-creadoras, la casa de una de ellas se dispuso como espacio de taller, así se propició un entorno de comodidad y confianza que permitió la movilidad entre los espacios y el desarrollo de dinámicas de juego dentro e, incluso, fuera de la creación.

A continuación compartimos los momentos y resultados más significativos de los talleres de creación:

\section{Lectura y apreciación de libros álbumes}

El momento inicial de todos los talleres se enfocó en propiciar una experiencia lectora que les permitiera a las niñas acercarse a los lenguajes y narrativas del libro álbum, e identificar las diversas maneras en que pueden escribir e ilustrar su propia obra.

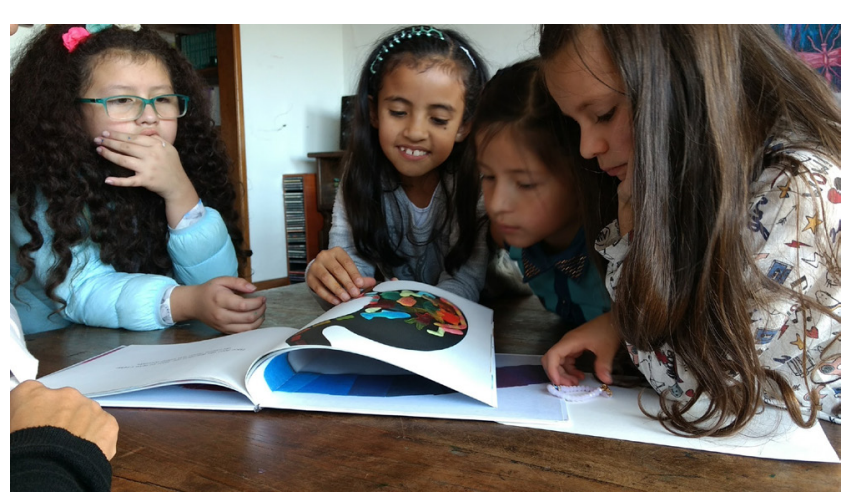

Figura 11. Lectura de La coleccionista de abuelas. Fuente: elaboración propia.

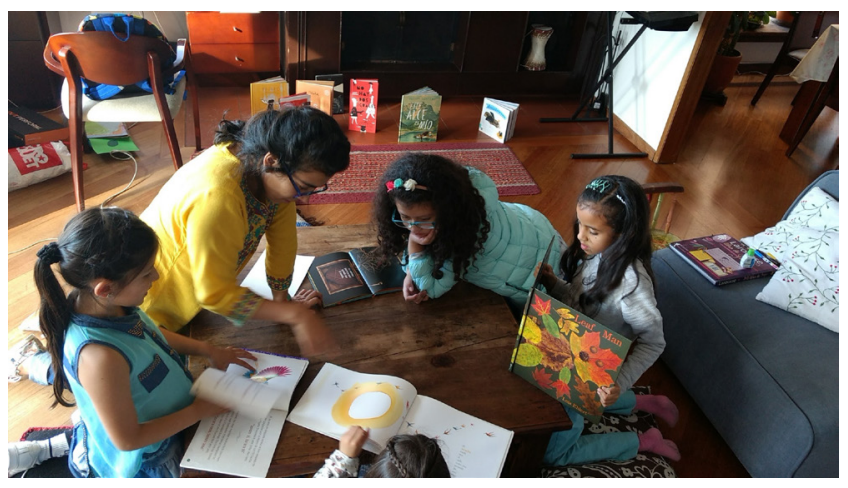

Figura 12. Lectura de texto e imágenes.

Fuente: elaboración propia.

\section{Lluvia de ideas}

Este es uno de los momentos decisivos de la creación, aquí nacen los cuestionamientos, el qué y el cómo se quiere contar, el porqué contarlo, de allí crecen las ideas que se trabajarán de manera colectiva para concretar una historia. Siete voces, todas en busca de encontrarse en la emoción de una idea, que lograra conjugar los pensamientos.

Muchas ideas surgieron y algunas se desarrollaron en boceto, e incluso fragmentos de historias, pero distantes de una unidad narrativa y estética, de manera que se volvía a empezar con un nuevo enfoque o propuesta, proveniente de las ideas previas construidas colectivamente.

A continuación un fragmento de una idea trabajada en el grupo:

Un libro sobre los niños de Colombia y yo voy a hacer una niña de Málaga y se llama Rosa, y su animal es un caballo, allá todo tiene muchas montañas, hay animales, como una cabra y allá me gusta mucho porque está toda mi familia y es muy significativo para mí ese lugar (Sofía, 8 años, co-creadora, 1 de abril de 2017). 


\section{Investigación}

Cada oportunidad de una posible historia potenció el ejercicio de la investigación, se implementaron dispositivos como: celulares, computadores y tabletas para el uso de motores de búsqueda en línea, con los que las niñas estaban familiarizadas; estos recursos permitieron acceder a información bibliográfica y visual sobre los temas de interés, propiciando un acercamiento a la realidad que inspiró sus construcciones narrativas y visuales.

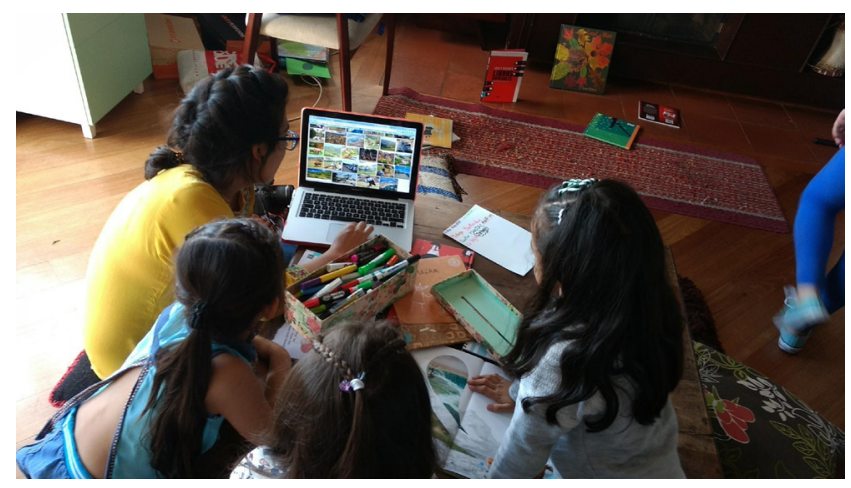

Figura 13. Taller de investigación.

Fuente: elaboración propia.

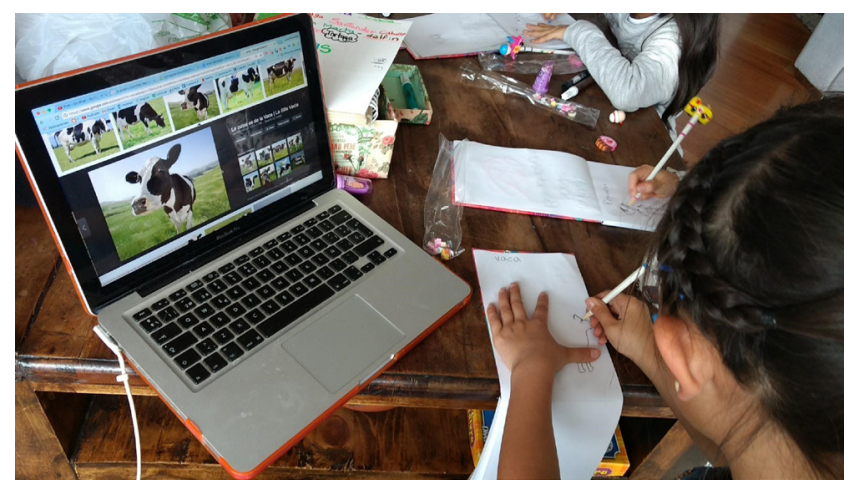

Figura 14. Taller de investigación.

Fuente: elaboración propia.

\section{Escritura}

El proceso de creación para un libro álbum requiere ser registrado y en este caso se comenzó con el relato oral, para luego de manera individual escribir una historia, hasta lograr de forma colectiva un guion, página a página. La visualización narrativa es la que permite dar forma a lo que se desea contar; en ese sentido, el ejercicio escritural acompañó la creación de historias, y permitió ordenar y poner en movimiento a las futuras imágenes y textos. Todo este proceso estuvo encaminado a la búsqueda de una voz narrativa que conjugara los deseos y el sentir de cuatro niñas y tres adultas.

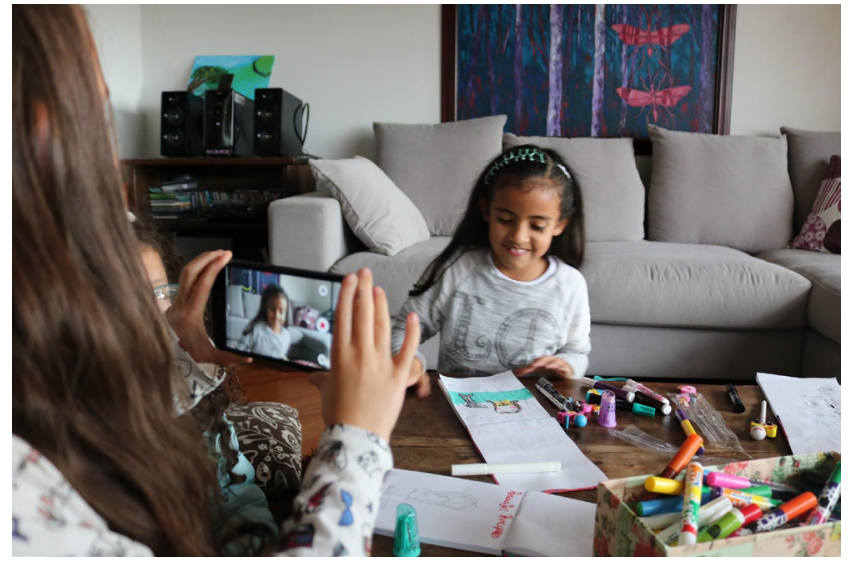

Figura 15. Taller de escritura.

Fuente: elaboración propia.

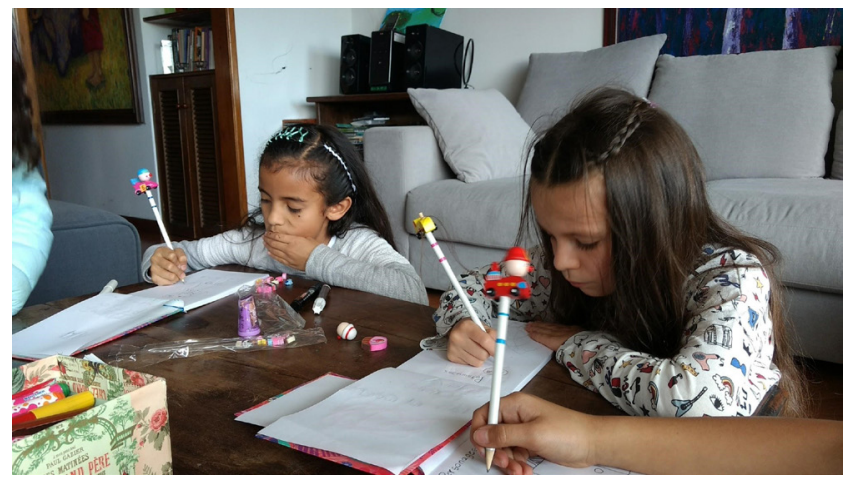

Figura 16. Taller de escritura.

Fuente: elaboración propia.

\section{Ilustración}

Cada taller fue planteado hacia la exploración de diversos materiales, en la búsqueda, desde una consideración visual y estética, de elementos que se lograran conectar con lo que se deseaba contar. Así se inició la construcción de personajes y escenarios, tratando de que los materiales y las formas comunicaran inicialmente un deseo personal para luego conjugarse con uno colectivo.

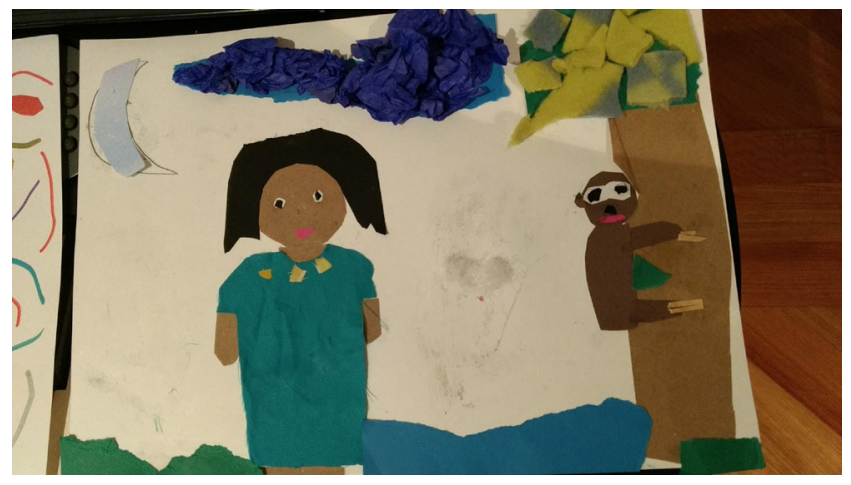

Figura 17. Taller de ilustración.

Fuente: elaboración propia. 


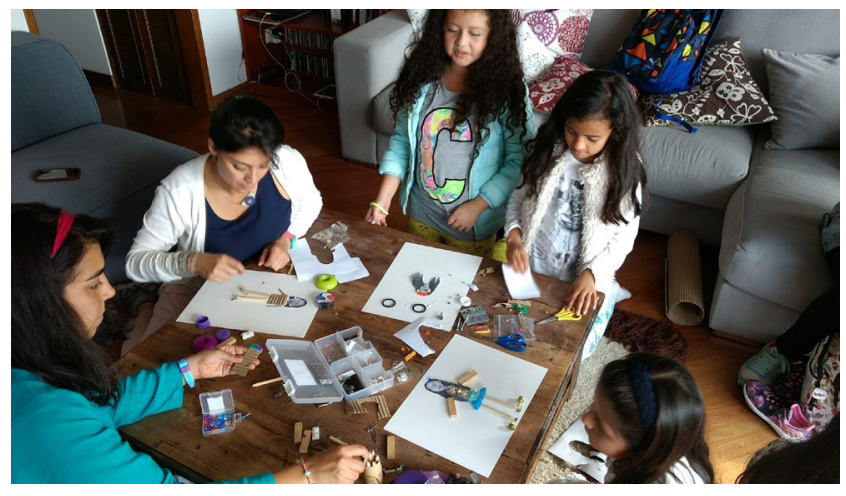

Figura 18. Taller ilustración, creación de personajes.

Fuente: elaboración propia.

\section{Aprendizajes}

Puede inferirse entonces que en el camino de la creación no hay límites, no hay una ruta trazada, esta se va develando en cada avance, con cada nueva idea; de esta manera se genera un sinfín de posibilidades válidas que se van encadenando a través del sentir y la experiencia del creador y su obra.

Y cuando se habla de un ejercicio de creación en colaboración con niños y niñas, su naturaleza cambia, se agudiza, pues requiere desde el primer momento una disposición del ser por encontrarse con el otro, por evocar espacios de encuentro entre pares, basados en la confianza, el intercambio de saberes e incluso en la construcción de lazos afectivos, para llegar a generar una serie de factores sin los cuales no sería posible desarrollar un trabajo de co-creación. Dichos factores van desde el primer contacto a niños y padres/cuidadores con una propuesta llamativa y de su interés, que brinde una posibilidad real de participación para lograr un compromiso que permita mantener su constancia en el proceso, así como la disposición de un espacio ameno, cercano, donde los niños sientan la comodidad que propicia una buena experiencia; elementos cruciales que para esta investigación representaron la posibilidad de una conclusión exitosa del ejercicio.

Otro gran protagonista es el juego, como eje del proceso creativo cuando se trabaja de la mano con niños, pues es uno de los principales movilizadores de historias y experiencias en la infancia; en ese sentido se propicia en los niños un encuentro provisto del goce y el disfrute, ambos necesarios en la tarea de descubrir el mundo e iniciar la construcción del propio, es decir de la subjetividad que es la materia prima de la creatividad e imaginación; dos pilares para esta investigación.

Puede afirmarse, entonces, que dar voz a los niños en la creación de contenidos infantiles nos permitió observar la capacidad innata y auténtica de asombro que ellos poseen, su potencial creativo para resolver a partir de la imaginación y la experiencia, ejercicios de creación narrativa y visual fundamentales para la concepción de contenidos literarios como el libro álbum.

Los niños son agentes creadores por naturaleza, que logran desplegar todo su potencial al tener la oportunidad y disposición de un entorno que los invite a contar, crear y representar para otros, la posibilidad de ser escuchados, como sujetos de lenguaje, de experiencias y saberes, creadores de imágenes e historias construidas desde sus vivencias y mezcladas con su imaginación.

Este camino de investigación/creación que continúa y se propone concluir con la presentación de un libro álbum hecho en colaboración con niños, no es más que una puerta abierta y una invitación a seguir aprendiendo desde la investigación y la práctica sobre el mundo de la creación de contenidos para público infantil, la producción de libros álbum en Colombia, los imaginarios de infancia y la participación de los niños en estos contextos.

\section{Referencias}

Cassany, D. (1996). La cocina de la escritura. Barcelona: Anagrama.

Chericián, D. (1995). Escribir para niños. Hojas de Lectura, 37: 11-13.

Correa, O. (2011). Enfoque Reggio Emilia. Cuenca, Ecuador: Universidad de Cuenca.

Cuervo, C.; Flórez, R. (2015). El regalo de la escritura. Bogotá: Universidad Nacional de Colombia.

Daza, S. (2009). Investigación - creación. Un acercamiento a la investigación en las artes. Horizontes Pedagógicos, 11(1): 87-92.

Díaz, F. (2007). Leer y mirar el libro álbum: ¿ un género en construcción? Bogotá: Norma. 
Kohan, S. A. (2016). Escribir para niños. Todas las claves para escribir lo que los niños quieren leer. Barcelona: Alba.

Milstein, D.; Clemente; Á.; Danta-Whitney, M.; Guerrero, A. L., Higgins, M. (eds.). (2011). Encuentros etnográficos con niñ@s y adolescentes. Entre tiempos y espacios compartidos. Buenos Aires: Miño y Dávila.

Ministerio de Educación República de Chile (2009) Ver para leer. Acercándonos al libro álbum. Santiago de Chile.
Quinto, B. (2005). Los talleres en educación infantil. Espacio de crecimiento. Barcelona: Graó.

Soriano, M. (1995). La literatura para niños y jóvenes: Guía de exploración de sus grandes temas. Buenos Aires: Colihue SRL.

Vian, I. (1995). Escribir para niños. Hojas de Lectura, 37: 8-10.

Vidal, R. (1976). Au pied de la lettre. París: Éditions Universitaires. 